\title{
How to Care for Your Team During a Crisis
}

\author{
Theodore L. Waldron (Texas Tech University) \\ James C Wetherbe (Texas Tech University)
}

KEYWORDS: Leadership, human resources, crisis management.

Walt Disney nailed it when he said that good customer relations begin with good employee relations. Fred Smith, the courageous entrepreneur and founder of FedEx, felt that way too, and his company slogan reflects it: People-Service-Profit

Both large companies and smaller, newer ventures are now facing a huge challenge putting their employees first as the COVID-19 crisis sidelines workers and business. Nearly 1 in 5 families have lost work during the pandemic. This has created a compelling challenge for businesses to show that their leadership cares about current and laid-off employees.

Whether the company is a new entrepreneur-led venture or an established firm, how employees are treated during this crisis will influence their attitudes and commitment when the crisis is over. This article provides guidance on how organizations can show they care -- through a framework that we call "CARE:"

- Communicate Plans

Accentuate Solidarity

Reward Perseverance

Empower Productivity

\section{Communicate plans}

Tell your people what's happening, what's going to happen, and how long these circumstances might persist. In other words, provide them with a plan, even if it changes (and it will). It's critical to give them the right information in the right way.

Your team will want to know how operations will change (e.g., facility closures), who will and won't continue to work, where work will occur and in what form, what types of support exist for employees, and what the timeline may look like.
In terms of how to communicate, provide a central repository of information that answers employee FAQs; limit communications to those who convey key insights; and refrain from repeating communications throughout the company's hierarchy.

Nordstrom has exemplified how to communicate plans to employees. The company detailed the impact of its operational changes on various types of employees (store, warehouse, back office, etc.), in addition to providing guidance on related factors like corporate travel, events and hiring. The company also designated certain executives as the official word on the crisis plans, but gave lower-level managers leeway to explain how the plans affect their specific work groups. Nordstrom also provided an internal COVID-19 information hub for employees.

Although the impact of the pandemic for your business continues to evolve, providing employees with a concrete plan creates confidence in your leadership and brings some measure of stability to their lives.

\section{Accentuate solidarity}

Let your people know, through what you say and do, that you and other organizational leaders are with them throughout this unprecedented situation.

Empathize with your employees as they experience the social and economic challenges created by the COVID-19 pandemic. The powerful message should be that you are weathering the storm with them and looking out for their well-being as much as possible. Respect for employee well-being and care-giving is crucial at this time.

Consider engaging in "servant leadership," which will send a powerful message to your team. This may mean taking on duties normally handled by your staff, so they can stay home and comply with social distancing measures or to heal if they are sick. It can also mean 
taking voluntary pay cuts, like the $50 \%$ reduction taken by Marriott's senior executives, in order to maintain employees' jobs and pay. In other instances, leadership might make decisions expressly designed to protect employee health, such as installing sanitizing equipment, even if these decisions temporarily take away from market-oriented initiatives.

Tom Bihn, a Seattle-based manufacturer of hand-made travel goods, is an example of a company that has done this well. Along with expressing verbal concern for employee well-being, the company's leadership team installed contactless sinks in restrooms, staggered lunch breaks, increased workspace separation, and installed an industrial air filtration system. While letting their employees stay home and tend to their families, the leadership team shouldered the burden of continuing to design and manufacture product, to fulfill orders, and to engage in philanthropic efforts-the embodiment of a skeleton crew. The CEO volunteered to learn how to cut and sew fabric, while the $\mathrm{COO}$ came up with ways for the factory to produce washable masks for health care professionals with diminished supplies.

Creating an environment where COVID-19 represents a shared-rather than an individual- experience may mitigate the feelings of isolation and desperation from having to work remotely or to remain home without work. The act of bringing everyone together during a time of crises will reinforce their sense of identification and belonging with your company.

\section{Reward perseverance}

Give your people something back for supporting your company before and during the pandemic. Such efforts may take on a more financial bent to combat the economic hardship employees are experiencing at the moment.

Some potent ways to give back include paying salaries and benefits to those unable to work, offering unpaid leave when paid time off is not possible, and helping those laid off to find work with companies that are hiring (e.g., Amazon and CVS).

Companies who have enough money may go so far as to offer raises and bonuses to essential employees who continue to work, or even to help employees directly affected by COVID-19 with uncovered medical bills or other related expenses.
BJ's Wholesale Club and Netflix are examples of company who've rewarded perseverance. Beyond ensuring at least two weeks paid leave for employees unable to work, BJ's increased wages and bonuses for employees who continue to work in its stores. Hourly workers in stores, warehouses, and the home office will earn two dollars more per hour for at least the next few weeks. Managers in stores and warehouses will receive bonuses ranging from $\$ 500$ to $\$ 1,000$.

Netflix has put together a $\$ 100$ million relief fund for studio production staff on pandemic-forced hiatuses. Additionally, the company provided $\$ 15$ million in emergency relief to out-of-work studio staff in countries where it produces much of its proprietary entertainment content, with another million dollars going to various organizations assisting unemployed actors.

Supporting employees during this extremely trying time may go a long way in ensuring their loyalty and dedication, now and as circumstances return to normal.

\section{Empower productivity}

To the extent possible, make it possible for people to keep working. Three factors matter here: defining tasks, allowing work flexibility and providing resources.

Define tasks by giving your employees who remain on the job the details on what they will do, where they will do it, what they should achieve, and when it should get done. Look for opportunities to re-deploy workers to tasks of heightened importance during the pandemic, such as efforts in the restaurant industry to use existing waitstaff to make curbside or home deliveries. Make sure you know how new public health measures, such as social distancing and hand washing/sanitizing, will affect how the work is done. For employees who have been laid off, be as transparent as possible about the prospects of resuming their positions and when it might happen.

Allow your employees some flexibility in where, when, and how they work. If employees are working from home, trust that they are giving their full effort and don't try to monitor their time and require proof of productivity. For employees working on site, allow them to set schedules around personal obstacles associated with COVID-19, such as dealing with the closure of childcare centers or caring for sick relatives.

Finally, make sure your employees have the resources 
they need to continue their work. Some may need laptops, monitors, VOIP phones, internet service, and training on how to work remotely.

Benchmark Mortgage has exemplified how to empower productivity by employees. Benchmark, headquartered in Dallas, corporate set up VPNs for employees nationwide to access their onsite desktops from remote locations. Some of the company's branches, which were set up to be fully mobile before the pandemic, had already provided their employees with laptops and allowed them to take home ancillary equipment like computer monitors.

Giving employees what they need to remain productive in the face of extraordinary upheaval may help to give them a purpose and keep them engaged until the effects of the pandemic dissipate.

\section{Conclusion}

To conclude, we advocate for giving employees your CARE during this difficult time. Doing so may cultivate long-lasting goodwill with the people who constitute your company's backbone. 